\title{
The Efficacy and Short- and Long-Term Side Effects of Radioactive lodine Treatment in Pediatric Graves' Disease: A Systematic Review
}

\author{
Sarah L. Lutterman ${ }^{a}$ Nitash Zwaveling-Soonawala ${ }^{a}$ Hein J. Verberne ${ }^{b}$ \\ Frederik A. Verburg ${ }^{c}$ A.S. Paul van Trotsenburg ${ }^{a}$ Christiaan F. Mooij $^{\mathrm{a}}$ \\ aDepartment of Pediatric Endocrinology, Emma Children's Hospital, Amsterdam UMC, University of Amsterdam, \\ Amsterdam, The Netherlands; ' Department of Radiology and Nuclear Medicine, Amsterdam UMC, University of \\ Amsterdam, Amsterdam, The Netherlands; ' Department of Radiology and Nuclear Medicine, Erasmus University \\ Medical Center, Rotterdam, The Netherlands
}

\section{Keywords}

Graves' disease · Pediatric Graves' disease · Radioactive iodine $\cdot$ Side effects

\begin{abstract}
Background: Graves's disease (GD) is the most common cause of hyperthyroidism. Maximal $30 \%$ of pediatric GD patients achieve remission with antithyroid drugs. The majority of patients therefore require definitive treatment. Both thyroidectomy and radioactive iodine (RAI) are often used as definitive treatment for GD. However, data on efficacy and short- and long-term side effects of RAI treatment for pediatric GD are relatively scarce. Methods: A systematic review of the literature (PubMed and Embase) was performed to identify studies reporting the efficacy or short- and longterm side effects of RAI treatment in pediatric GD. Results: Twenty-three studies evaluating 1,283 children and adolescents treated with RAI for GD were included. The treatment goal of RAl treatment changed over time, from trying to achieve euthyroidism in the past to aiming at complete thyroid destruction and subsequent hypothyroidism in the last 3 decades. The reported efficacy of a first RAI treatment when aiming at hypothyroidism ranged from 42.8 to $97.5 \%$, depending on the activity administered. The efficacy seems
\end{abstract}

karger@karger.com www.karger.com/et

Karger!"
(C) 2021 The Author(s)

Published by S. Karger AG, Base

This is an Open Access article licensed under the Creative Common Attribution-NonCommercial-4.0 International License (CC BY-NC) (http://www.karger.com/Services/OpenAccessLicense), applicable to the online version of the article only. Usage and distribution for commercial purposes requires written permission. to increase with higher RAl activities. When aiming at hypothyroidism, both short- and long-term side effects of treatment are very rare. Long-term side effects were mainly seen in patients in whom treatment aimed at achieving euthyroidism. Conclusion: $\mathrm{RAl}$ is a safe definitive treatment option for pediatric GD when aiming at complete thyroid destruction. When aiming at hypothyroidism, the efficacy of treatment seems to increase with a higher RAI activity. Prospective studies are needed to determine the optimal RAI dosing regimen in pediatric $G D$.

(c) 2021 The Author(s)

Published by S. Karger AG, Basel

\section{Introduction}

In adults and children, hyperthyroidism is mostly caused by Graves' disease (GD) $[1,2]$. Treatment options for GD include antithyroid drugs (ATDs), thyroidectomy, and radioactive iodine (RAI). In Europe, ATDs are the preferred first-line treatment modality in newly diagnosed pediatric GD patients [3-5]. Unfortunately, the relapse frequency of hyperthyroidism is high in this age

A.S. Paul van Trotsenburg and Christiaan F. Mooij contributed equally.
Correspondence to:

Christiaan F. Mooij, c.mooij@amsterdamumc.nl 
group, with only $20-30 \%$ reaching long-lasting remission after 2 years of ATD treatment [5]. Therefore, most pediatric GD patients eventually require definitive treatment.

Both thyroidectomy and RAI are proven effective therapeutic measures for hyperthyroidism. The choice between RAI and total thyroidectomy is a contentious topic and will reflect local expertise and opinion. The final decision on what option to follow will involve shared decision-making including the patient and parents, focusing on the (dis)advantages of each option and local expertise. Total thyroidectomy is a safe treatment option in pediatric GD patients, especially if performed by high-volume surgeons [6]. Only in a minority of pediatric patients, irreversible complications of surgery like permanent hypocalcemia $(2.5 \%)$ or recurrent laryngeal nerve injury $(0.4 \%)$ have been reported [6]. Furthermore, thyroidectomy is potentially associated with general surgical risks and consequences, like postoperative bleeding, infections, and a permanent scar. RAI treatment using iodine-131 has been carried out for 80 years. RAI is taken up by thyrocytes and stored within the thyroid follicle. The radioactive isotope decays by emitting $\beta$-radiation, causing DNA damage leading to thyrocyte apoptosis and necrosis. In the past, in many areas of the world, the aim of RAI treatment for GD was to achieve euthyroidism; hypothyroidism was considered a side effect. The current American Thyroid Association and European Thyroid Association treatment guidelines both state that in pediatric GD patients, the RAI treatment goal is to achieve hypothyroidism (ablative RAI treatment) [4, 7]. The main reason to aim for complete thyroid destruction in pediatric patients is to prevent the need for additional RAI therapy (and thus extra radiation exposure) as low RAI activity has been associated with poor remission rates. In addition, the current guidelines state that aiming at hypothyroidism will minimize the future risk of malignant transformation of viable but radiation-damaged thyrocytes [7]. RAI treatment should be avoided in cases with active Graves' orbitopathy as it can result in exacerbation, and specific preparatory measures prior to RAI administration have to be taken in patients with inactive Graves' orbitopathy [8].

Data on the efficacy of RAI treatment, the optimal RAI activity, and its short- and long-term side effects in pediatric GD patients are scarce. However, such data are necessary to aid in deciding on the modality of definitive treatment. Several approaches are used to determine the RAI activity to be used in pediatric GD patients. RAI activity may be calculated based on estimated thyroid weight or based on full dosimetry using the result of a RAI uptake, either probe or scan based $[9,10]$. Alternatively, administration of a fixed amount of RAI activity has been reported [9]. In adult patients undergoing RAI treatment for GD, radiation thyroiditis is reported as a short-term side effect in $1.2 \%$ of the patients [11]. With respect to long-term side effects, there are some worries that RAI treatment at a younger age may increase the risk of other malignancies later in life [12]. In this study, we performed the first systematic review on the efficacy and short- and long-term side effects of RAI treatment in pediatric GD patients. Ideally, the results of this systematic review should be helpful in formulating an evidence-based advice on the optimal ablative RAI activity, preferably without short- or long-term side effects. An overview of available data on both the efficacy and side effects of RAI treatment may be helpful when counseling young patients and their parents who require definitive treatment for GD.

\section{Methods}

This systematic review was performed following the PRISMA 2009 guidelines [13].

\section{Literature Search}

The literature search for this review, using the electronic databases PubMed and Embase, was performed in July 2020 and was further not limited to a specific period. The following search terms were used: Graves' disease, RAI, and efficacy or side effects. For all main terms, synonyms were inserted. MeSH and tiab terms were combined to find a wide range of articles. The exact search strategy used for both the PubMed and Embase database is available in online suppl. data (for all online suppl. material, see www.karger. com/doi/10.1159/000517174). The search was limited to studies in pediatric patients (age limit $<18$ years). Additional articles were searched by scanning the references of relevant articles and using the "related article" function of the databases.

\section{Study Selection and Quality Assessment}

Title and abstract screening was performed independently and blinded by S.L.L. and C.F.M. Full-text screening was performed by S.L.L. and discussed with C.F.M.; in case of disagreement, a third reviewer (A.S.P.v.T.) was consulted. Original studies reporting on the efficacy or on short- and long-term side effects of RAI treatment in a minimum of 10 pediatric GD patients were included. When a study reported data on pediatric patients separate from adult patients, the study was also included. Full-text availability was the last inclusion criterion. Exclusion criteria were conference abstracts, review articles, and articles published in other languages than English, Dutch, German, French, Italian, or Spanish. Part of the full-text screening was a critical appraisal to evaluate the quality per study using the Critical Appraisal Skills Program checklist. The used checklist is designed for cohort studies and is therefore applicable to all of the included articles.

\section{Data Extraction}

Data extraction was performed by S.L.L. and was double-checked by C.F.M. Data on the treatment goal, efficacy, used RAI activity, and 


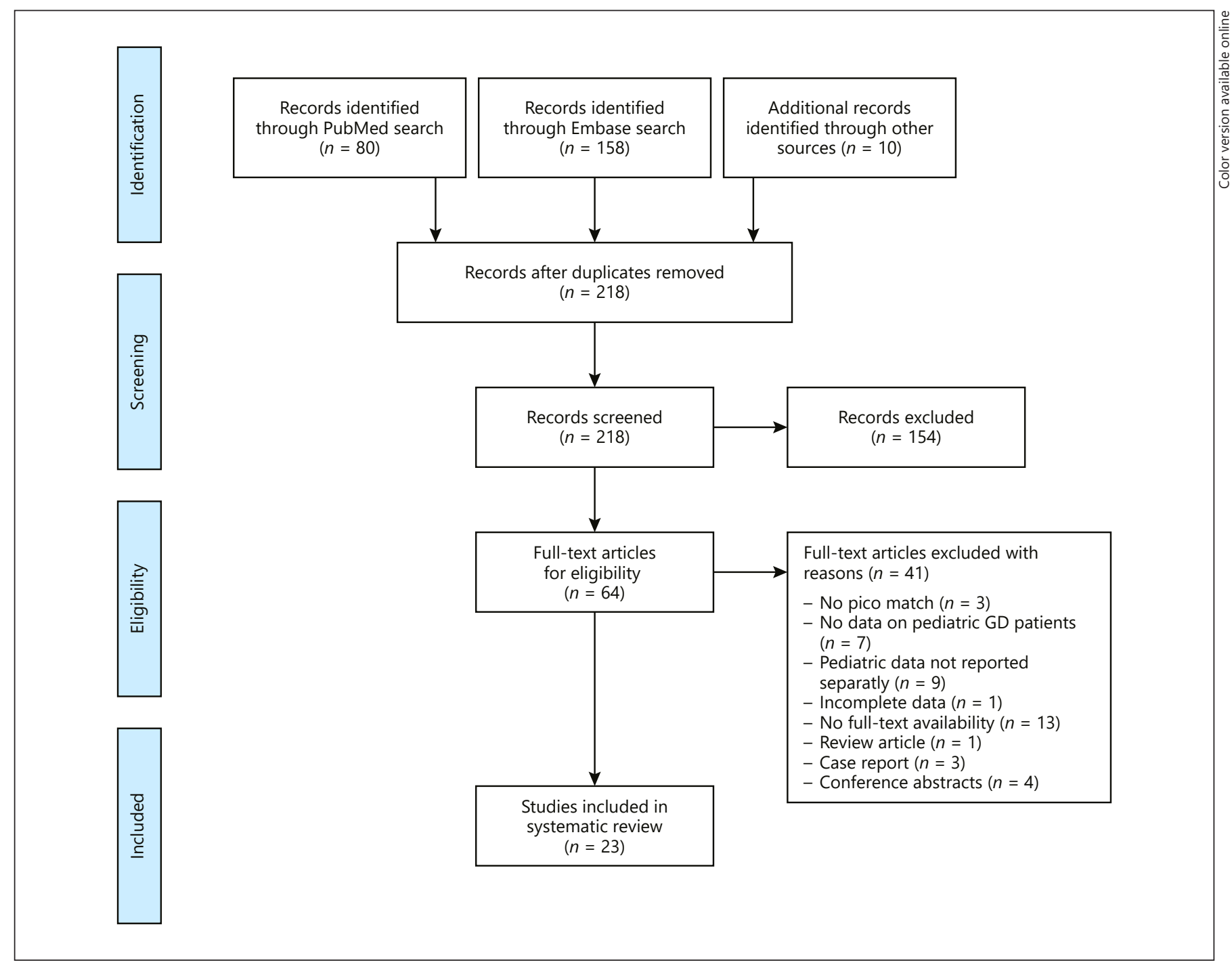

Fig. 1. Flowchart illustrating the results of the literature search on studies evaluating the efficacy and/or shortand long-term side effects of RAI treatment in pediatric GD patients. GD, Graves' disease; RAI, radioactive iodine.

side effects of treatment were collected. The side effects were classified as either long- or short-term side effects. For efficacy, we mainly focused on studies using ablative RAI treatment. For side effects, studies on RAI treatment that aimed at either ablation or euthyroidism were analyzed. Short-term side effects were defined as side effects that occurred within 3 months of RAI treatment, while long-term side effects occurred $>3$ months after RAI treatment.

\section{Results}

The PubMed and Embase searches were performed on July 16, 2020, and yielded 208 unique articles. Ten additional articles were identified via references reading. A total of 154 articles were excluded after title and abstract screening, and an additional 41 articles were excluded after full-text screening. Twenty-three retrospective observational cohort studies were included in this review (Fig. 1). Based on the quality assessment, the quality of 2 of the included studies was rated as good [14, 15], 18 studies as fair [16-33], and 3 studies as reasonable [34-36]. As reported RAI treatment protocols differed between studies or changed over time (including the treatment goal: aiming for eu- or hypothyroidism) and individual patient data were lacking, we were unable to perform a metaanalysis calculating the optimal iodine-131 activity aiming for hypothyroidism. 


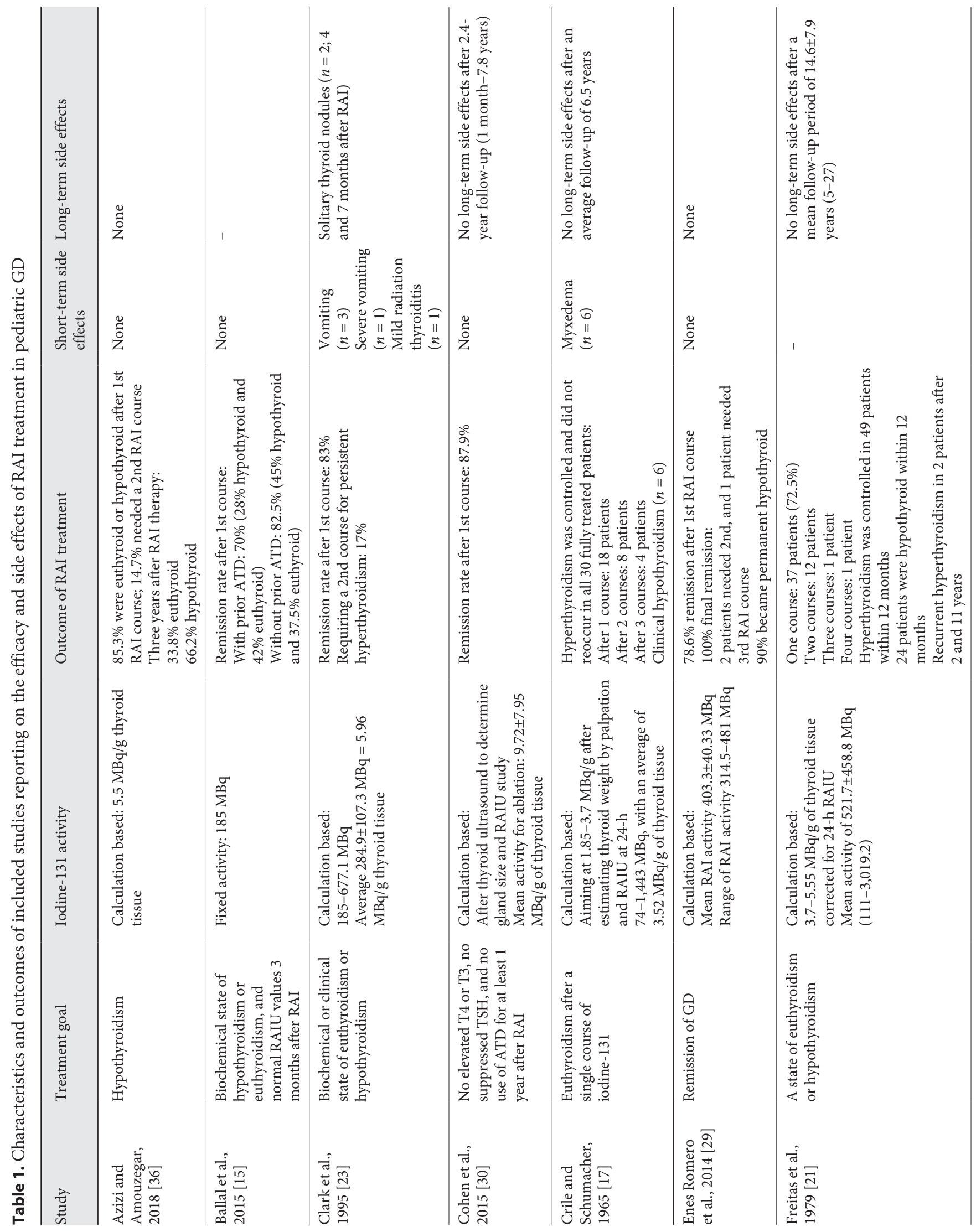




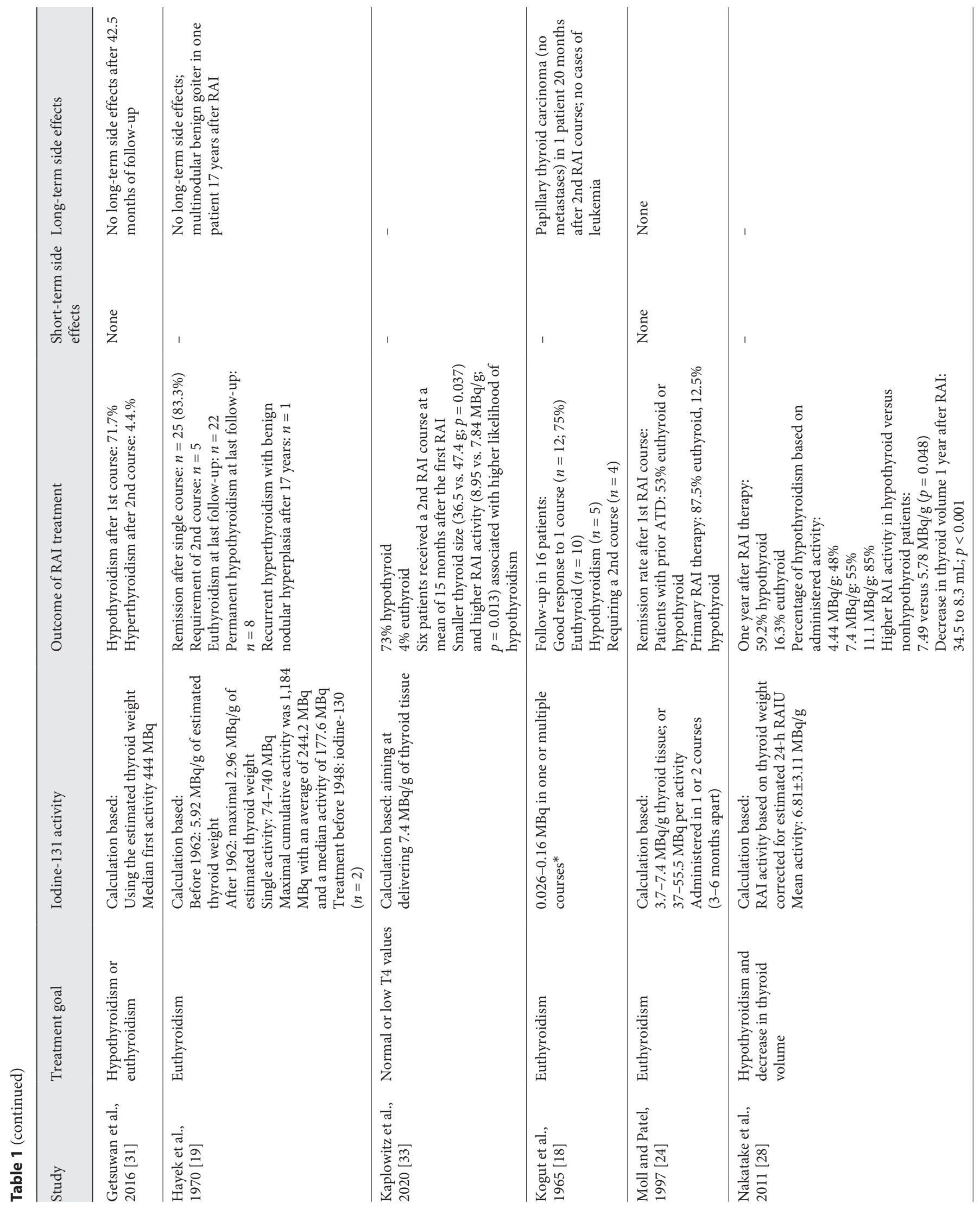




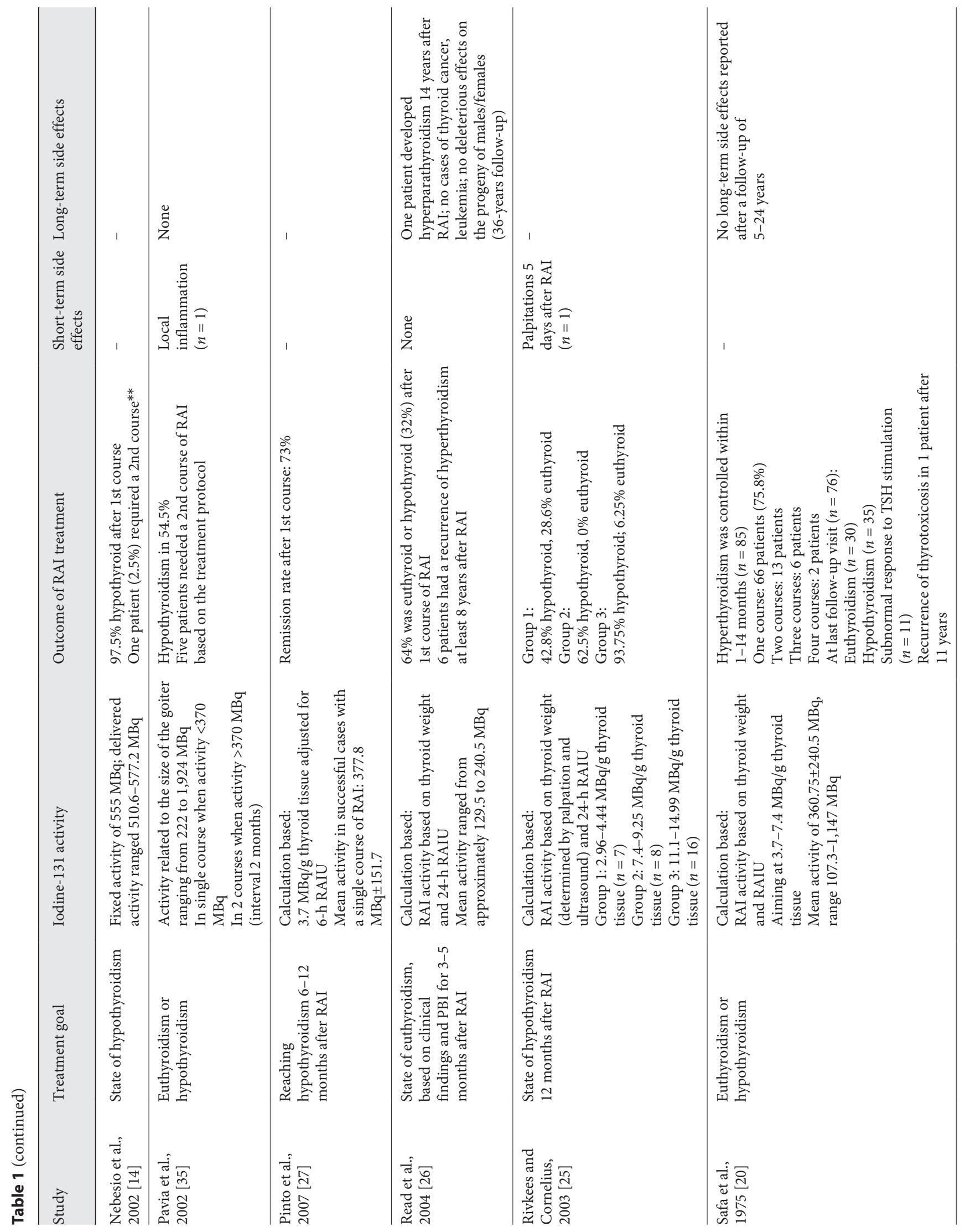




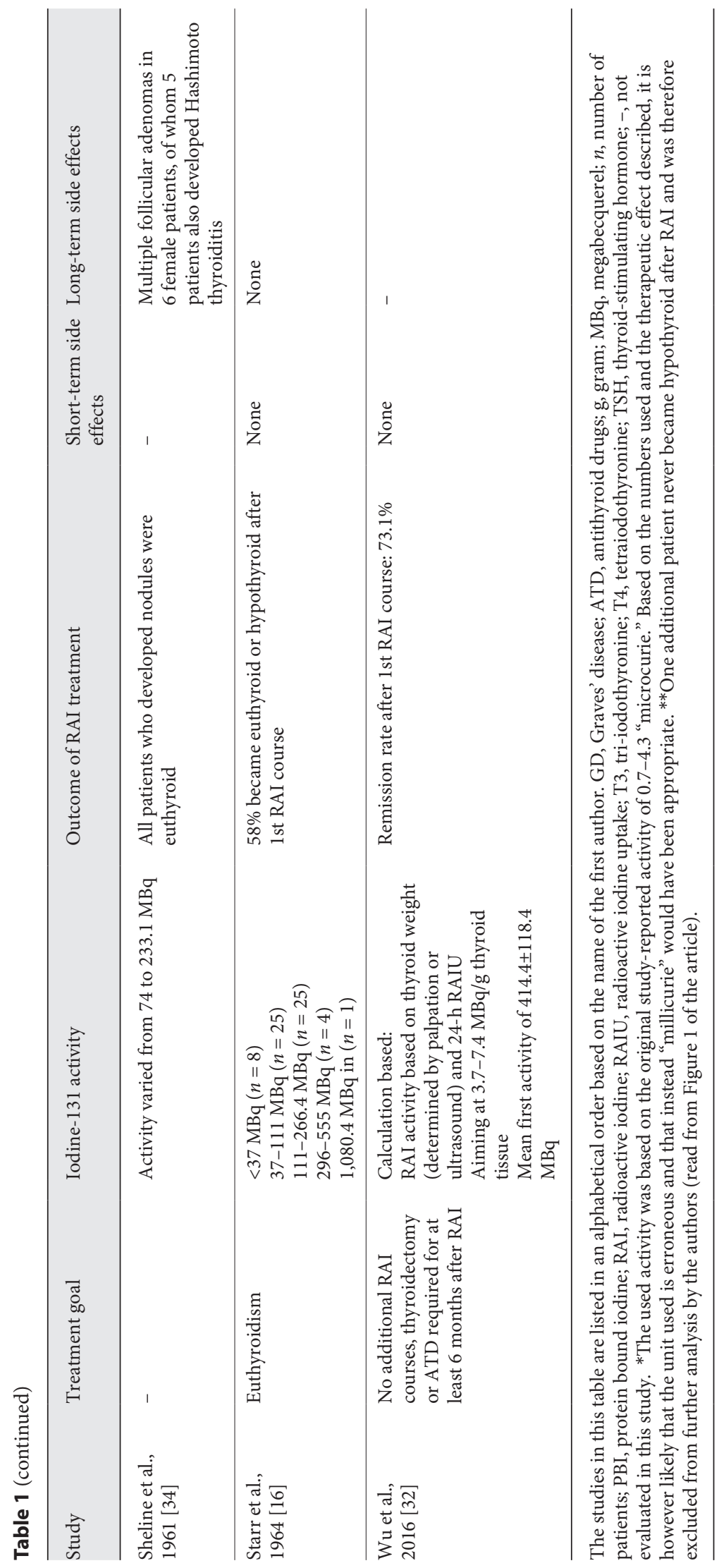




\section{Study Characteristics}

The 23 included studies reported on RAI treatment of 1,283 children and adolescents with GD. Study characteristics of the included studies regarding the study period, number of patients, gender of included patients, age at RAI treatment, and the indication for RAI treatment are shown in online suppl. Table 1. Extracted data on the applied iodine-131 activity (converted to megabecquerel $[\mathrm{MBq}])$, the efficacy of RAI treatment, and the short- and long-term side effects are shown in Table 1. Seventeen studies used a calculated activity of RAI [17, 19-33, 36], and 2 studies a fixed activity of RAI [14, 15]. In 4 studies, it was not clear how the activity of RAI was determined $[16,18,34,35]$. The way in which the efficacy of RAI treatment was evaluated differed between studies. In 13 of the 23 included studies, data on short-term side effects of RAI treatment are reported, and data on long-term side effects are reported in 15 studies. In most studies, the majority of patients was treated with ATDs prior to RAI treatment.

\section{The Efficacy of RAI Treatment in Pediatric GD}

The goal of RAI treatment - hypothyroidism or euthyroidism - differed between and even within included studies. Based on the current treatment goal of aiming at destruction of the thyroid gland, we analyzed data on studies using ablative RAI treatment. This, however, was the specific treatment goal in only 5 of the included studies, reporting on a combined total of 278 patients $[14,25$, $27,28,36]$. In these 5 studies, the reported efficacy after a first RAI treatment aiming at hypothyroidism ranged from 42.8 to $97.5 \%$, depending on the activity administered. When aiming at hypothyroidism, the efficacy appears to increase with a higher iodine-131 activity. The study by Nebesio et al. [14] was the only one aiming at hypothyroidism using a fixed RAI activity $(555 \mathrm{MBq}$; equals 15,000 microcurie $[\mu \mathrm{Ci}]$ ) resulting in hypothyroidism in $97.5 \%$ of the studied patients after 1 course of RAI. This fixed RAI activity is far more than used in the other studies based on the average thyroid weight in children. Pinto et al. [27] reported hypothyroidism in $73 \%$ of the patients after a first activity of $3.7 \mathrm{MBq} / \mathrm{g}$ thyroid tissue adjusted for RAI uptake. Azizi and Amouzegar [36] aimed for hypothyroidism using an RAI activity of 7.4 $\mathrm{MBq} / \mathrm{g}$ thyroid tissue and reported that $14.7 \%$ of the patients required a second cycle of RAI therapy, but did not specify the percentage of patients becoming hypothyroid after the first RAI activity (eventually $66.2 \%$ of the RAItreated patients were classified as hypothyroid). The studies by Nakatake et al. [28] and Rivkees and Cornelius [25] are the only 2 studies that retrospectively evaluated the efficacy of different RAI activities aiming at hypothyroidism. Nakatake et al. [28] reported hypothyroidism in $48 \%$ of the patients who received $4.44 \mathrm{MBq}(120 \mu \mathrm{Ci})$ of iodine-131 per gram of thyroid tissue. However, $85 \%$ of the patients who received $11.1 \mathrm{MBq}(300 \mu \mathrm{Ci})$ of iodine-131 per gram of thyroid tissue became hypothyroid [28]. In line with these findings, Rivkees and Cornelius [25] reported similar results: hypothyroidism was achieved in $42.8 \%$ of the patients receiving an activity of 2.96-4.44 $\mathrm{MBq}(80-120 \mu \mathrm{Ci})$ of iodine-131 per gram of thyroid tissue, while $93.75 \%$ of the patients who received 11.1-14.99 MBq (300-405 $\mu \mathrm{Ci})$ of iodine-131 per gram of thyroid tissue became hypothyroid. Based on these last 2 studies, administering a minimum activity of $11 \mathrm{MBq}$ but possibly a little $>15 \mathrm{MBq}$ of iodine-131 per gram of thyroid tissue seems necessary to achieve thyroid destruction in the vast majority of pediatric GD patients.

Several of the other included studies aimed at either euthyroidism or euthyroidism/hypothyroidism and are therefore not usable for formulating an evidence-based advice on the optimal RAI activity that aims at thyroid destruction. However, overall, the studies show that the efficacy seems to increase with a higher iodine-131 activity. All studies reported patients requiring additional RAI treatment because of persistent or recurrent hyperthyroidism. A detailed presentation of the reported efficacy of RAI treatment in all included studies is presented in Table 1.

\section{Short- and Long-Term Side Effects of RAI Treatment in Pediatric GD}

To evaluate the presence of side effects after RAI treatment, studies aiming at both euthyroidism and hypothyroidism were included. Short-term side effects of RAI treatment in pediatric GD patients were only rarely reported. Among them were vomiting $(n=4)$, radiation thyroiditis $(n=1)$, local inflammation $(n=1)$, palpitations $(n=1)$, and myxedema $(n=6)$. Reported long-term side effects included benign thyroid nodules $(n=6)$, multinodular benign goiter $(n=1)$, hyperparathyroidism $(n=1)$, and papillary thyroid carcinoma $(n=1)$. No additional cases of thyroid cancer, no cases of leukemia, and no impaired reproductive capacity were reported in the patients who received RAI treatment for pediatric GD, nor was there a reported increased frequency of congenital abnormalities in their offspring in studies with a long enough follow-up period. The cases of thyroid nodules, multinodular goiter, and thyroid carcinoma after RAI treatment were all reported in patients with RAI treatment not exclusively aiming at hypothyroidism. However, in 
these studies, a causal relation between RAI treatment and the development of thyroid nodules was not proven. Detailed information on the reported side effects of RAI treatment in the included studies is shown in Table 1.

\section{Discussion}

In this systematic review, we report the efficacy and short- and long-term side effects of RAI treatment in pediatric patients with GD. Twenty-three studies evaluating 1,283 children and adolescents with GD were included. In 5 studies, the specific treatment goal of RAI was hypothyroidism (including a total of 278 patients). In these studies, the reported efficacy of the first RAI treatment in achieving hypothyroidism ranged from 42.8 to $97.5 \%$, depending on the applied activity. Unfortunately, prospective studies evaluating the effect of different iodine-131 activities in the treatment of pediatric GD are lacking, hampering evidence-based activity advice. Yet, in the few retrospective studies in which RAI treatment aimed at hypothyroidism, a minimal activity of $11.1-14.99 \mathrm{MBq}$ of iodine-131 per gram of thyroid tissue seemed to result in hypothyroidism in $85-94 \%$ of pediatric GD patients. Short- and long-term side effects of RAI treatment in pediatric GD were very rare. Reported long-term side effects were benign thyroid nodules, multinodular benign goiter, hyperparathyroidism, and papillary thyroid carcinoma. These side effects affecting thyroid tissue were only reported in cases in which the RAI treatment aim was euthyroidism. However, it has not been proven that the abovementioned long-term side effects are caused by low-level thyroid irradiation. Overall, the data in this systematic review show that RAI aiming at hypothyroidism of the thyroid seems a safe definitive treatment option for pediatric GD. Evidence for the best dosing strategy to reach hypothyroidism after RAI treatment is still weak as only 2 retrospective studies evaluated the efficacy of different RAI activities $[25,28]$.

Ideally, the optimal RAI activity should result in 100\% efficacy without significant short- or long-term side effects. Based on the 2 studies reporting the effects of different RAI activities aiming at hypothyroidism, an activity of $11 \mathrm{MBq}$ but possibly a little $>15 \mathrm{MBq}$ per gram of thyroid tissue leads to an efficacy of $85-94 \%[25,28]$. In addition, Kaplowitz et al. [33] stated that a higher RAI activity was associated with a higher likelihood of hypothyroidism (8.95 vs. $7.84 \mathrm{MBq}$ per gram of thyroid tissue; $p=0.013$ ). Interestingly, none of the studies aiming at hypothyroidism reached $100 \%$ efficacy, meaning that a minority of patients may require a second RAI treatment to achieve

Radioactive Iodine in Pediatric Graves' Disease hypothyroidism. However, one may be reluctant to prescribe higher RAI activities for treatment of a benign thyroid disorder like GD as RAI has, at least theoretically, been associated with an increased risk of development of malignancies in other tissues than the thyroid later in life.

Recently, an association was reported between RAI treatment for benign adult thyroid disease and an increased risk of death from breast or gastric cancer many years later [37]. However, these results have been heavily criticized, and studies on this association in children are lacking [38]. Nevertheless, one should be prudent using higher RAI activities in the treatment of pediatric GD because of the (theoretical) risk of RAI-induced cancers later in life. None of the studies included in this review reported nonthyroidal malignancies or leukemia later in life, despite long-term follow-up after RAI treatment, up to 27 years in some studies $[17,19-21,26]$. Since all patients included in these 5 studies were treated with RAI between 1941 and 1973, new studies with a long follow-up are needed to determine the exact risk of secondary malignancies later in life after RAI treatment with dosing according to current treatment guidelines. The only reported case of malignancy was papillary thyroid carcinoma in a patient in whom RAI treatment aimed at euthyroidism [18]. Hypothetically, this side effect might not have occurred if treatment had aimed at thyroid destruction. Pediatric patients with differentiated thyroid carcinoma receive much higher activities of iodine- 131 for remnant ablation after thyroidectomy [39], varying from $1,100 \mathrm{MBq}$ $(29,729 \mu \mathrm{Ci})$ up to $7,400 \mathrm{MBq}(200,000 \mu \mathrm{Ci})$ in case of lung metastases. Even after the use of such high activities of RAI in pediatric differentiated thyroid carcinoma, an increased risk of secondary malignancies has thus far not been reported [40-42]. Therefore, one may assume that it is safe to apply somewhat higher activities than currently used for complete thyroid ablation in pediatric GD.

To our knowledge, this is the most extensive systematic review on the efficacy and short- and long-term side effects of RAI treatment in pediatric GD and therefore gives a good overview of the available data on outcome of RAI treatment in children and adolescents with GD. It is remarkable that in spite of the long history of RAI treatment in pediatric GD, the available studies only focused on activities administered and not on dosimetric parameters related to the actual radiation dose delivered to the thyroid. It is very well possible that individualization of administered RAI activity through more extensive dosimetry may not only increase efficacy but also minimize unnecessary exposure of other tissues than the thyroid. In many of the included studies, the procedure on determin- 
ing or estimating thyroid weight was not fully explained. It is well known that in healthy children, thyroid size increases with age $[43,44]$, and that in pediatric GD patients, the thyroid is frequently symmetrically enlarged. In our opinion, when dosing RAI per gram of thyroid tissue, thyroid ultrasound by an operator experienced in thyroid ultrasound is the most reliable way to determine thyroid size in pediatric GD patients and should be performed prior to RAI treatment to calculate the desired RAI activity. A major limitation of our study is that we were unable to perform a meta-analysis on the efficacy of RAI treatment in pediatric GD patients as treatment goals changed over time, dosing regimens differed between and changed within studies, and original data were lacking. Endpoints for efficacy were not consistently defined across the included studies. As a result, it is difficult to compare efficacy between studies. Only 5 retrospective studies reported efficacy data on ablative RAI dose of which only 2 studies evaluated the efficacy of different RAI doses $[25,28]$. Future prospective studies evaluating different RAI treatment strategies (fixed activity, calculated activity based on estimated thyroid weight, or activity based on full dosimetry) are needed to determine the best evidence-based RAI strategy for the treatment of pediatric GD. From the 5 studies in which RAI treatment specifically aimed at hypothyroidism $[14,25,27,28,36]$, only the study by Azizi and Amouzegar [36] reported on long-term side effects of RAI treatment. In this study, the follow-up duration after RAI treatment was not fully specified, but was probably between 1 and 3 years. In the other 4 studies, the follow-up duration was not specified or reported to be $<5$ years, and authors did not mention long-term side effects. Although this does not mean that their presence or absence was not assessed, this may point to reporting bias.

In conclusion, based on the results of this review, RAI treatment is a safe definitive treatment option in pediatric GD. Both short- and long-term side effects of RAI treatment are very rare. However, new studies focusing on the long-term risk of RAI-induced malignancies are needed to evaluate risks associated with current treatment guidelines. Also, new well-designed prospective studies are essential to come to a well-founded RAI dosing strategy in pediatric GD patients. Yet, based on the few retrospective studies on this subject, RAI treatment seems to be effective in achieving hypothyroidism in the majority of treated patients when 11-15 MBq (approximately 300-400 $\mu \mathrm{Ci}$ ) iodine-131 per gram of thyroid tissue is administered.

\section{Statement of Ethics}

For this type of study (systematic review), formal consent is not required.

\section{Conflict of Interest Statement} close.

The authors report that they have no conflicts of interest to dis-

\section{Funding Sources}

The authors did not receive any funding for the present work.

\section{Author Contributions}

All authors conceived the idea of evaluating the efficacy and short- and long-term side effects of RAI treatment in pediatric GD patients. S.L.L. and C.F.M., and if necessary A.S.P.v.T., performed the literature search including title and abstract screening, full-text screening, and data abstraction. S.L.L., C.F.M., and A.S.P.v.T. discussed the abstracted data and took the lead in writing this review. All authors discussed previous versions of the manuscript and agreed to the submission of the final version.

\section{References}

1 De Leo S, Lee SY, Braverman LE. Hyperthyroidism. Lancet. 2016 Aug 27;388(10047): 906-18.

2 Hanley P, Lord K, Bauer AJ. Thyroid disorders in children and adolescents: a review. JAMA Pediatr. 2016 Oct 1;170(10):1008-19.

3 Leger J, Kaguelidou F, Alberti C, Carel JC. Graves' disease in children. Best Pract Res Clin Endocrinol Metab. 2014 Mar;28(2):233-43.

4 Kahaly GJ, Bartalena L, Hegedüs L, Leenhardt L, Poppe K, Pearce SH. 2018 European thyroid association guideline for the manage- ment of Graves' hyperthyroidism. Eur Thyroid J. 2018 Aug;7(4):167-86.

5 Leger J, Carel JC. Diagnosis and management of hyperthyroidism from prenatal life to adolescence. Best Pract Res Clin Endocrinol Metab. 2018 Aug;32(4):373-86.

6 Zaat AS, Derikx JPM, Zwaveling-Soonawala N, van Trotsenburg ASP, Mooij CF. Thyroidectomy in pediatric patients with Graves' disease: a systematic review of postoperative morbidity. Eur Thyroid J. 2021 Mar;10(1): $39-51$.
7 Ross DS, Burch HB, Cooper DS, Greenlee MC, Laurberg P, Maia AL, et al. 2016 American thyroid association guidelines for diagnosis and management of hyperthyroidism and other causes of thyrotoxicosis. Thyroid. 2016 Oct;26(10):1343-421.

8 Bartalena L, Baldeschi L, Boboridis K, Eckstein A, Kahaly GJ, Marcocci C, et al. The 2016 European thyroid association/European group on Graves' orbitopathy guidelines for the management of Graves' orbitopathy. Eur Thyroid J. 2016 Mar;5(1):9-26. 
9 Stokkel MP, Handkiewicz Junak D, Lassmann M, Dietlein M, Luster M. EANM procedure guidelines for therapy of benign thyroid disease. Eur J Nucl Med Mol Imaging. 2010 Nov; 37(11):2218-28.

10 Silberstein EB, Alavi A, Balon HR, Clarke SE, Divgi C, Gelfand MJ, et al. The SNMMI practice guideline for therapy of thyroid disease with 131I 3.0. J Nucl Med. 2012 Oct;53(10): 1633-51.

11 Sundaresh V, Brito JP, Thapa P, Bahn RS, Stan $\mathrm{MN}$. Comparative effectiveness of treatment choices for Graves' hyperthyroidism: a Historical Cohort Study. Thyroid. 2017 Apr; 27(4):497-505.

12 Rivkees SA, Dinauer C. An optimal treatment for pediatric Graves' disease is radioiodine. J Clin Endocrinol Metab. 2007 Mar;92(3):797800.

13 Moher D, Shamseer L, Clarke M, Ghersi D, Liberati A, Petticrew M, et al. Preferred reporting items for systematic review and metaanalysis protocols (PRISMA-P) 2015 statement. Syst Rev. 2015 Jan 1;4:1.

14 Nebesio TD, Siddiqui AR, Pescovitz OH, Eugster EA. Time course to hypothyroidism after fixed-dose radioablation therapy of Graves' disease in children. J Pediatr. 2002 Jul;141(1): 99-103.

15 Ballal S, Soundararajan R, Singh H, Garg A, Chopra S, Bal C. Influence of prior carbimazole on the outcome of radioiodine therapy in pediatric and adolescent Graves' disease. Nucl Med Commun. 2015 Jun;36(6):566-72.

16 Starr P, Jaffe HL, Oettinger LJr. Late results of I-131 treatment of hyperthyroidism in seventy-three children and adolescents. J Nucl Med. 1964 Feb;5:81-9.

17 Crile GJr, Schumacher OP. Radioactive iodine treatment of Graves' disease. Results in 32 children under 16 years of age. Am J Dis Child. 1965 Nov;110(5):501-4.

18 Kogut MD, Kaplan SA, Collipp PJ, Tiamsic T, Boyle D. Treatment of hyperthyroidism in children. Analysis of forty-five patients. N Engl J Med. 1965 Feb 4;272:217-21.

19 Hayek A, Chapman EM, Crawford JD. Longterm results of treatment of thyrotoxicosis in children and adolescents with radioactive iodine. N Engl J Med. 1970 Oct 29;283(18):94953.

20 Safa AM, Schumacher OP, Rodriguez-Antunez A. Long-term follow-up results in children and adolescents treated with radioactive iodine (131I) for hyperthyroidism. N Engl J Med. 1975 Jan 23;292(4):167-71.
21 Freitas JE, Swanson DP, Gross MD, Sisson JC. Iodine-131: optimal therapy for hyperthyroidism in children and adolescents? J Nucl Med. 1979 Aug;20(8):847-50.

22 Hamburger JI. Management of hyperthyroidism in children and adolescents. J Clin Endocrinol Metab. 1985 May;60(5):1019-24.

23 Clark JD, Gelfand MJ, Elgazzar AH. Iodine-131 therapy of hyperthyroidism in pediatric patients. J Nucl Med. 1995 Mar;36(3): 442-5.

24 Moll GWJr, Patel BR. Pediatric Graves' disease: therapeutic options and experience with radioiodine at the University of Mississippi Medical Center. South Med J. 1997 Oct; 90(10):1017-22.

25 Rivkees SA, Cornelius EA. Influence of iodine-131 dose on the outcome of hyperthyroidism in children. Pediatrics. 2003 Apr; 111(4 Pt 1):745-9.

26 Read CHJr, Tansey MJ, Menda Y. A 36-year retrospective analysis of the efficacy and safety of radioactive iodine in treating young Graves' patients. J Clin Endocrinol Metab. 2004 Sep;89(9):4229-33.

27 Pinto T, Cummings EA, Barnes D, Salisbury S. Clinical course of pediatric and adolescent Graves' disease treated with radioactive iodine. J Pediatr Endocrinol Metab. 2007 Sep; 20(9):973-80.

28 Nakatake N, Fukata S, Tajiri J. Prediction of post-treatment hypothyroidism using changes in thyroid volume after radioactive iodine therapy in adolescent patients with Graves' disease. Int J Pediatr Endocrinol. 2011 Nov 7; 2011:14.

29 Enes Romero P, Martín-Frías M, de Jesús M, Caballero Loscos C, Alonso Blanco M, Barrio Castellanos R. [Efficacy of treatment with I(131) in paediatric Graves disease]. An Pediatr. 2014 Jan;80(1):16-20.

30 Cohen RZ, Felner EI, Heiss KF, Wyly JB, Muir $\mathrm{AB}$. Outcomes analysis of radioactive iodine and total thyroidectomy for pediatric Graves' disease. J Pediatr Endocrinol Metab. 2016 Mar;29(3):319-25.

31 Getsuwan S, Wiromrat P, Panamonta O, Panamonta M, Paireepinas S. Effectiveness and safety of radioactive iodine therapy in childhood Graves' disease in Khon Kaen, Thailand. J Med Assoc Thai. 2016 Aug;99(Suppl 5): S112-9.

$32 \mathrm{Wu}$ VT, Lorenzen AW, Beck AC, Reid VI, Sugg SL, Howe JR, et al. Comparative analysis of radioactive iodine versus thyroidectomy for definitive treatment of Graves disease. Surgery. 2017 Jan;161(1):147-55.
33 Kaplowitz PB, Jiang J, Vaidyanathan P. Radioactive iodine therapy for pediatric Graves' disease: a single-center experience over a 10year period. J Pediatr Endocrinol Metab. 2020 Mar 26;33(3):383-9.

34 Sheline GE, Lindsay S, Mccormack KR, Galante M. Thyroid nodules occurring late after treatment of thyrotoxicosis with radioiodine. J Clin Endocrinol Metab. 1962 Jan;22: 8-18.

35 Pavia C, Villanueva J, Valls C, Mane S, Cedo $\mathrm{J}$. Radioiodine therapy for Graves disease in adolescents: analysis of 11 patients. Endocrinologist. 2002 Jan-Feb;12(1):17-9.

36 Azizi F, Amouzegar A. Management of thyrotoxicosis in children and adolescents: 35 years' experience in 304 patients. J Pediatr Endocrinol Metab. 2018 Jan 26;31(2):159-65.

37 Kitahara CM, Berrington de Gonzalez A, Bouville A, Brill AB, Doody MM, Melo DR, et al. Association of radioactive iodine treatment with cancer mortality in patients with hyperthyroidism. JAMA Intern Med. 2019 Aug 1;179(8):1034-42.

38 Greenspan BS, Siegel JA, Hassan A, Silberstein EB. There is no association of radioactive iodine treatment with cancer mortality in patients with hyperthyroidism. J Nucl Med. 2019 Nov;60(11):1500-1.

39 Lebbink CA, Dekker BL, Bocca G, Braat AJAT, Derikx JPM, Dierselhuis MP, et al. New national recommendations for the treatment of pediatric differentiated thyroid carcinoma in the Netherlands. Eur J Endocrinol. 2020 Oct;183(4):P11-18.

40 Chow SM, Law SC, Mendenhall WM, Au SK, Yau S, Mang O, et al. Differentiated thyroid carcinoma in childhood and adolescenceclinical course and role of radioiodine. Pediatr Blood Cancer. 2004 Feb;42(2):176-83.

41 Mihailovic J, Nikoletic K, Srbovan D. Recurrent disease in juvenile differentiated thyroid carcinoma: prognostic factors, treatments, and outcomes. J Nucl Med. 2014 May;55(5):710-7.

42 Tamam M, Uyanik E, Edís N, Mulazimoglu M, Ozpacaci T. Differentiated thyroid carcinoma in children: clinical characteristics and long-term follow-up. World J Nucl Med. 2020 Jan-Mar;19(1):28-35.

43 Ueda D. Normal volume of the thyroid gland in children. J Clin Ultrasound. 1990 Jul-Aug; 18(6):455-62.

44 Garcia-Ascaso MT, Ares Segura S, Ros Perez P, Pineiro Perez R, Alfageme Zubillaga M. Thyroid volume assessment in 3-14 year-old Spanish children from an iodine-replete area. Eur Thyroid J. 2019 Jul;8(4):196-201.
Radioactive Iodine in Pediatric Graves' Disease
Eur Thyroid J 2021;10:353-363

DOI: $10.1159 / 000517174$ 